
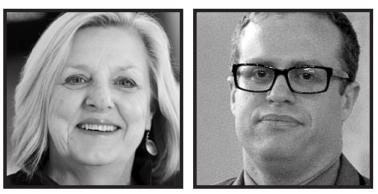

\title{
Artful Inquiry in the E-learning Journal
}

\author{
Kathryn Grushka and Aaron Bellette, University of Newcastle
}

\begin{abstract}
E-learning is transforming the learning landscape. This paper focuses on photomedia participatory inquiry in an e-feed learning culture. It harnesses the benefits of artful inquiry and elaborates on interactive reflective opportunities when using participatory research methods. Student e-learning journal examples and the teacher reflective voice demonstrate how artful inquiry accommodates critical and reflective actions for new creative outcomes. The methods described and analyzed may have relevance to educators considering applying multi-semiotic learning approaches within e-learning journals as digital platforms become central to digital learning and communication of ideas.
\end{abstract}

\section{Embracing Change}

s the learning landscape shifts to accommodate social media, educators
must embrace this change. In all learning that seeks creative and adaptive
thinking as a learning outcome, the potential benefits of e-learning and how it can facilitate creative engagement across existing and new learning platforms is critical. This paper focuses on an example of a photomedia participatory e-feed learning culture in a first-year tertiary photomedia course. The course harnesses the benefits of artful inquiry within an e-learning environment while accessing the benefits of the traditional art studio learning (Hetland, Winner, Veenema, \& Sheridan, 2007). It elaborates on the rationale of the pedagogical design and ways the photomedia teacher has designed interactive reflective and creative opportunities for the students. It assesses and reflects on the affordances of artful inquiry approaches applied through participatory research methods. It uses student e-learning journal examples and the 
teacher reflective voice to demonstrate how artful inquiry, in the e-learning context, is applied in order to accommodate the critical and reflective actions of both the student and teacher as they observe, reflect, dialogue, and interpret their learning actions for new creative outcomes. The methods described and analyzed may have relevance to educators who are considering the benefits of 21st century digital literacies and multi-semiotic learning approaches, particularly when using e-learning journals as reflective and creative learning sites and for the communication of self-learning and new ideas to others.

\section{Background: New Media and Photomedia Curriculum Design}

Curriculum design and its practices have entered a new paradigm shift based on the assumption that new digital technologies, or multimodal devices, are now our social reality and shape learning in new participatory ways (Grushka, Donnelly, \& Clement, 2014). The shift in curriculum design acknowledges the complexity and range of emergent new semiotic communicative practices that carry fluid, co-constructed, and mobile characteristics. As authentic learning, it must respond to the learning preferences of individual students and the new extra-linguistic field of semiotics or edusemiotics (Danesi, 2010). This field includes, "sign signification, such as aesthetic products, visual communication, new media, advertising, narratives, material culture, film and gaming or other performance based acts such as dance, body movement or drama, anything that is underpinned by sign based activity" (Grushka, Donnelly, \& Clement, 2014, p. 363). Students now seek to access knowledge and to represent it across these different modes and media. Teachers will now have to consider the affordances of these new modes in their students' learning and develop practices that allow them to access their new digital literacy skills and the ever-increasing possibilities opening up in these new digital learning cultures.

This shift in curriculum thinking corresponds to the call for learner-centered pedagogies that are greater than the application of a new technology and offer students greater levels of agency, social connectedness, and autonomy. They embed the creative opportunities that are intuitively present for students who work across semiotic systems (Mishra \& Yadav, 2013) and provide innovative learning opportunities through participation, collaboration, and/or production (Lloyd, 2013). They are pedagogies that can focus on creative inquiry and performance; learner-designed learning; inductive and creative modes of reasoning and collaborative problem solving through the iterative 
stages of inquiry, analysis, production, and presentation. Photomedia curriculum and the teaching and researching of student learning in photomedia education for the digital and mobile generation encounters these challenges (Jones, 2010). Images are now ubiquitous for the digital generation. This poses a dilemma for photography educators seeking more considered visual, aesthetic, and reflective dispositions from their students (McLoughlin \& Lee, 2008).

\section{Artful Methods}

Artful methods acknowledge that learning is based (Dewey, 1938), embodied (Jevic \& Springgay, 2008), and draws on memory work, our self-reflective capacities, and our adaptive or creative brains. Artful inquiry as a pedagogical method accommodates feelings and memories and the active role they play in each individual's perceptions of phenomena and learning. Artful inquiry echoes the work of neuroscience in acknowledging that human knowledge emerges from different sensory experiences - and that these experiences rely on affective memory and modality specific memory, such as visual, auditory, sensory, and motor memory, and that conceptual memory emerges from these origins, their usage, and the naming of experiences for meaning making (Arnold, 2013). This learning is not only multimodal, but also multi-temporal, carrying past and present embodied experiences, increasingly captured digitally, carried by an array of cultural forms now stored and accessed endlessly through digital means.

Moreover, artful methods acknowledge the evolutionary role of the arts and aesthetic experience in building adaptive skills that are essential for managing change (Dissanayake 2008) and how artful inquiry builds reflective sensibilities that are critical when considering the significance of affect on learning and memory work. We record events in our brains, based on the inferences we make when perceiving them, and later, in the narratives we use to communicate events (Damasio, 2006). These narratives can shift the order and emphasis of things, and links affect in learning as fundamental to adaption (Immordino-Yang \& Damasio, 2007).

Artful pedagogies bring the perception of openness to experience as they employ higher-order interactive processes, plasticity, and creativity (Silvia, Nusbaum, Berg, Martin, \& O'Connor, 2009). The methods link observation, experience, intuition, intellectual, emotional, and social dimensions of learning with creative problem-solving to generate a myriad of methodologies for investigating phenomena, to create new knowledge or processes, and to connect or integrate memories as prior knowledge and processes across an array of disciplines in the generation of new meanings. 
Artful inquiry is also able to respond to the e-learning participatory culture and the habits of its learners as they build their capacities to drive different individual performative acts through the communicative and collaborative potential of multimodal platforms. In so doing, they are constantly reshaping their learner selfreflexivity repertoire. This self-reflective space is increasingly open to liminal possibilities that trigger our thinking, our actions, and our learning. As events or experience in the virtual world contain learning at the borders of the past and future, how we measure learner self-reflexivity and learner insight will need to respond the media flows generated by digital realities together with their re-mixing between their material experiences, storytelling as narrative, visual, and other textual forms, including poetry and performance, combined within e-feed productive processes. Artful inquiry that combines visual and poetic forms of self-reflection accommodates such reflective practices (Butler-Kisber \& Poldma, 2010). This space resists the educational rhetoric of knowledge uniformity and accepts uncertainty (Sameshima \& Irwin, 2008).

\section{Photographic Participatory Inquiry}

Photographic Participatory Inquiry (Grushka, Bellette, \& Holbrook, 2014) is foregrounded by the visual. It was conceptualized for the teacher/educator as both a pedagogy and research methodology that acknowledges that critical insights into teaching and learning are performatively acquired through action and reflection within learning acts and the conversations between the student and teacher. It embeds arts inquiry methods, acknowledging the reflexivity, creativity, and adaptive thinking that underpins transformative learning. It centers visuality (Stafford, 2007) as both a legitimate design and socio-cultural research method in response to the cognitive work that images do and to its increasing role in multi-semiotic digital communication structures (Bailey \& Van Harken, 2014). It embeds the ideas of participatory methods where the researcher and the student participant are co-creators of qualitative data (Vince \& Warren, 2008) and the active role of images generated by mobile devices to communicate ideas and events. It pays attention to the significance of reading images (decoding), thinking in images and creating (encoding) or designing images that collectively become a new visual vocabulary (Emanuel \& Challons-Lipton, 2013). It also acknowledges the growth of knowledge visualization methods through collaborative interactive graphics (Eppler, 2013) and aligns with the conversation on edusemiotics (Danesi, 2010) or multiliteracies (Cope \& Kalantzis, 2009; Lankshear \& Knobel, 2004) in the representation of contemporary knowledge.

Photographic participatory inquiry (Grushka, Bellette, \& Holbrook, 2014) that centers images embeds self-reflective participatory action research (Denzin \& Lincoln, 
2005; Gallagher \& Kim, 2008; Mockler \& Sachs, 2011) and draws specifically on the Critical Practitioner Action Research model (Kemmis, 2011). This model acknowledges the complexity of co-constructed meanings when reflecting and acting and sees critical practitioner action research as the ability to be able to share learning experiences in order to transform and change pedagogical practices. The student(s) and educator are co-participants in the exploration of the learning phenomenon. Together, they gather evidence of learning in order to reflect upon how the historical consequences of past cognitive acts influence current learning. It also pays attention to the cultural-discursive, social, and material acts, as well as the learning dispositions as performatively consequential for both parties. In collaboration the teacher and the student reflect on action, in action, and for action (Grushka, McLeod, \& Reynolds, 2005). Reflection on action is informed by the memory of past learning experiences and awareness of personal learning preferences. Reflection in action sees the teacher and the student modifying their actions when working and paying attention to adaptive or transformative opportunities. Reflection for action will see them critically identifying how they can adapt their actions to achieve improved learning outcomes or, in the case of the educator, improve their participatory pedagogies.

Participatory inquiry draws on the research insights of $A / r /$ tography (Irwin \& De Cosson, 2004; Springgay, Irwin, \& Kind, 2005) located within arts education that acknowledges the educator as carrying the multiple roles of artist, researcher, and teacher, and is inherently about practice-based living inquiry. A/r/tographical work is concerned with exploring and paying attention to the conceptual ideas that can be rendered artistically and educationally through relational conditions of aesthetic inquiry (Irwin \& Springgay, 2008). It seeks to pay attention to these cognitive and conceptual moments located within teacher-student dialogue. It focuses explicitly on the tangential ideas that can be grasped by both parties and draws on a range of multimodal learning tools such as video, photography, analytical writing, and reflective learning narratives. It also responds to an increasing dialogue in research about the significance and benefits of arts-based self-study methods (Hostetler, Macintyre Latta, \& Sarroub, 2007; Pithouse, Mitchell, \& Weber, 2009; Samaras \& Roberts, 2011) and accommodates an ethico-aesthetic paradigm (Guattari, 1995) or what Springgay (2011) refers to as building a capacity for ethical pedagogical sensibilities. Such an approach acknowledges that teachers' learning and their subsequent pedagogies have been shaped by personal events, media, and institutional structures and that participatory inquiry requires them to acknowledge and balance their own subjectivity production as teacher with a critical lens that values the inter-personal relationships, multiple creative and aesthetic sensibilities, and cognitive complexities that surround the experience, stories, memory work, and affective responses of their students. 
The learning data generated within participatory inquiry methods, whether material or virtual, when sensitively negotiated is able to create what Angharad Valdivia (2002) terms an "ethical theory of voice" (p. 435) and has the potential for new openings and connections that emerge as a productive force, self-becoming-other (Deleuze, 1987, 1990). Teacher self-reflection can support students to learn that aesthetic and ethical decisions are linked and they learn to value that they too can exercise ethical choices in an array of collective or collaborative learning contexts.

\section{The Study With a Focus on Artful Inquiry in the e-Learning Journal}

The larger, ethics approved study underpinning this paper, Photographic Participatory Inquiry in researching the teaching and learning of photography in the e-learning environment, is located in a higher education and multimedia e-learning environment of the photomedia student. It synthesizes both critical participatory action research in education (Kemmis, 2011) and artful research approaches (Butler-Kisber \& Poldma, 2010; Finley, 2008) in order to investigate the affordances of using Visual or Photographic Participatory Inquiry and associated participatory digital technologies (Gubrium \& Harper, 2009) within an e-learning journal for digitally online oriented photomedia students.

In particular, the research presented and reported in this paper focuses on how the photomedia teacher has designed and embedded arts inquiry as an interactive aesthetic, reflective, and creative learning opportunity for the students utilizing the student e-learning journal. The multimedia tools used by the photomedia educator are illustrated and reflected upon for their potential to inform the teacher research project. The study seeks to identify the benefits of using e-learning platforms through the analysis of student work samples, conversations, and teacher critical reflections, in order to question, refine, and build knowledge about teaching digital photography in an e-learning environment. The paper will focus on how the students record in their e-journal: their research about a concept or the work of photographers, their thinking about the intentional act of capturing an image (pre-visualization) (Adams, 1934a, 1934b); their subsequent written and visual critical and reflective responses about the images they captured; and finally how they intend to manipulate their digital images in the computer in order to accommodate their original intentions and their intended audience (post-visualization) (Uelsmann, 2001 to 2002). These insights about the photographic visualization phases of their digital image production are captured through analysis of the e-learning journal content and through photo and video elicitation methods. Together, they inform the potential of this e-learning tool to accommodate the critical and reflective actions of both the student and teacher. 
The findings will be communicated through student and teacher reflective voices and examples of photomedia and reflective narrative posts.

\section{Photographic visualization as reflective learning using gopro and screen capture} tools. Researching photographic participatory inquiry in an e-learning environment and its associated visual and arts-informed methods have been fully elaborated for their rationale and potential to investigate the personalized, participatory, and productive pedagogies for a networked learning society in "Researching Photographic Participatory Inquiry in an E-learning Environment" (Grushka, Bellette, \& Holbrook, 2014). The paper above provides a more complete description of the theoretical underpinnings of the research methods presented in this paper. The photographic visualization Phases 1 and 2 (pre- and post-visualization) and the documenting and reflecting role of the e-learning journal and the students' creative processes and how they are operationalized within critical participatory research are summarized below (Phase 3). In Phase One, the pre-visualization process, the students are asked to record the act of taking images using GoPro video capture. Video edits from GoPro footage can contextualize the before and after image capture moments for the student. They are then required to analyze this edited data, interrogating their motives, both aesthetic and affective, for why a particular image or visual moment was recorded through the camera. In Phase Two, the post-visualization phase, the students use screen-capture video software to analyze their Phase One images. This software can capture all the students' aesthetic and technical processes, and record them chronologically in the computer. Any subsequent changes to the image or aesthetic decision about the post-visualization stages can be tracked for a deeper understanding of their reflections and intentions as they consider the audience and their own learning insights. As the computer records multiple iterations of images and technical processes, these can be screen captured, then shared online through the web or mobile devices. The selection, sharing, and reflection can be almost instantaneous and can become routine. Students are comfortable with collaborative acts and they are also adept at repeating processes multiple times untill resolution is reached.

The e-learning journal in the photomedia participatory research. Within the e-learning journal Phase Three, the best opportunities to reveal the benefits of participatory inquiry can be seen. The e-journal brings together digital photos, digital image processing, video and audio recordings and other related files to inform the photo and video elicitation methods (Blinn \& Harrist, 1991; Harper, 2002), visual analysis methods (Pink, 2007), and the role of the visual journal in arts research (Grauer \& Naths, 1998). The e-learning journal captures information as digital artefacts or data that can then be accessed and harnessed to build critical and reflective photographic 
practices as an extended dialogue. It allows access to reflective and creative thinking beyond the quick flicking and sharing of image ideas and technical notes through mobile devices. Phases 1 and 2 data is uploaded into the e-journal, edited, overlaid, and reflected upon. The e-journal becomes the platform for collaborative dialogue using photo- and video-elicitation interview approaches. The insights from the interviews allow both the teacher/researcher and student to inform their pedagogical learning or assessment. These moments provide opportunities for active learning (Drew \& Mackie, 2011), and they emerge when the narrated voices of the student and the teacher/researcher are overlaid and together new co-constructed insights are possible.

Participatory inquiry as active learning occurs when connections between aesthetic spaces within dialogical encounters between student, teacher, and other audiences in the generation of meanings are actively reflected upon. Such a consciousness has been termed, "interaction aesthetics" (Xenakis \& Arnellos, 2013) or the investigation of aesthetic choices when making images for particular audience responses. This is significant as increasingly photographic practices are entering a wide range of professional fields. The student/ photographer/artist is guided in the e-learning journal to employ levels of aesthetic, conceptual, and reflective inquiry using interactive reflection. Such reflection is only possible in a blended studio/e-learning framework where visual and verbal narratives can be built upon and inform photographic practice.

E-learning journal. The e-learning journal takes the form of a blog. It is the hub that facilitates the documentation of learning as a chronological documented process. This does not mean that the journal contains a fixed structure or linear thinking process, but a platform that can be customized. What it does is it affords students a systematic reference point for their learning moments, which can be accessed and revisited. It is also designed to contain the content of the photomedia teaching unit.

The following section elaborates on the structure and pedagogy of the blog. The brief for the e-journal starts with the following quote: "Never allow yourself to be hurt by what you imagine to be criticism by a teacher, nor allow yourself to remain elated because of praise. These feelings are barriers in your way, not conductors of it" (author unknown).

The intention of the e-learning journal is to not only contain the students' best work, but also to actually show the process, reflections, and development of projects throughout the semester and to be inspired by the learning of others. 
The students are encouraged and given permission to experiment and learn from mistakes and to articulate a process to facilitate growth and development for future projects. Fundamentally, the e-learning journal is used for displaying and documenting all of the students' work and assessment tasks. Participants are informed: "This journal is FOR YOU. Avoid treating it as an assessment task. MAKE IT YOURS" (Student Unit Information).

The rationale for the e-learning journal is to encourage the students (participants) to learn and put into practice research, experimentation of technical and aesthetic skills, documenting of their ideas and process for projects, and also reflection on each stage of the project. As the content of the blog can be customized and arranged according to individual preferences, it must require the students to demonstrate a clear set of skills. These include: i) Passion for the visual-sourced widely beyond photographs; ii) Observation and analyze other photographs; iii) Examination of field trends in aesthetic representation; iv) Reflection on self-what you love, hate, feel, despise, struggle with, think, and seek to understand on your creative journey; v) Documentation of work processes; v) Documentation of artists of significance and the critical relevance of their practice; and vi) how all of the above research and reflection relates to their own photographic projects. Finally, they are directed to locate resources widely and not be afraid to change ideas.

The documentation within the e-journal is as follows: the participants worked within a defined bushland space to shoot the project images with a head-mounted GoPro Camera. The camera recorded the shooters' eye-level perspective from a wideangle view to capture a minimum of four to six final images. On returning to the studio, the participants downloaded the images and began the editing. The participants create a video of their editing process via QuickTime. Once the editing process was finished, the next step was the reflection process of the project via the e-learning journal. The participants had access to the following data for their reflection processes: raw camera images, edited final images, Go Pro footage, and screen capture software.

Students subsequently condensed and curated the raw data as a reflection piece in their e-journal. The student participants were not limited by any descriptive process for this task and were encouraged to set their own analysis criteria. Some participants did a comparative analysis of their wide-angle GoPro bushland shots before editing the image, while some focused on the screen shot before and after editing processes, adding a written brief analysis. Other students would post clips of the GoPro footage and screen-capture edits, reflecting on what they felt were important moments within the decision-making process. All of the students reflected on different elements of the 
project with different degrees of depth, but overall the students engaged effectively with the process. Some students did multiple blog posts and others did very little as they reflected on how they could improve their process for future projects.

In the final participatory stages, students were encouraged to consider the reflections of their peers and to participate in video or photo-elicitation semi-structured interviews at the start and end of the unit. The open-ended questions were organized to seek descriptive analysis of the participants' photographic thinking and making. Questions such as 1) Describe what you were thinking and doing throughout this process of shooting the project; 2) Describe emotions felt in the construction of imagery from the GoPro footage; 3) How successful did you think you were in creating your image?; 4) How do you believe your image conveys your message to your intended audience?; 5) What photographic techniques have you used in the creation of your imagery? Finally the student participants were asked to reflect upon how they had improved their images and how their own practice compared to other photographers. The interviews are integral to the learning process and would be commonly used in studio pedagogies (Hetland et al., 2007) and reflective studentteacher learning moments.

\section{Findings for the E-learning Journal: Student Examples}

The students who participated in the Photographic Participatory Inquiry in researching the teaching and learning of photography in the e-learning environment agreed to share their rich data source of images, written words, and audio recordings. The following examples show a variety of different methods in the e-learning journal blog as interactive graphics to create, reflect, integrate, and apply as knowledge visualization (Eppler, 2013).

The first example (below) is from Felicity. She began her journal by first posting her selected images. She then posted screen shots of her GoPro footage of important images that she later edited. This visual post was also accompanied by a written analysis of her process. 

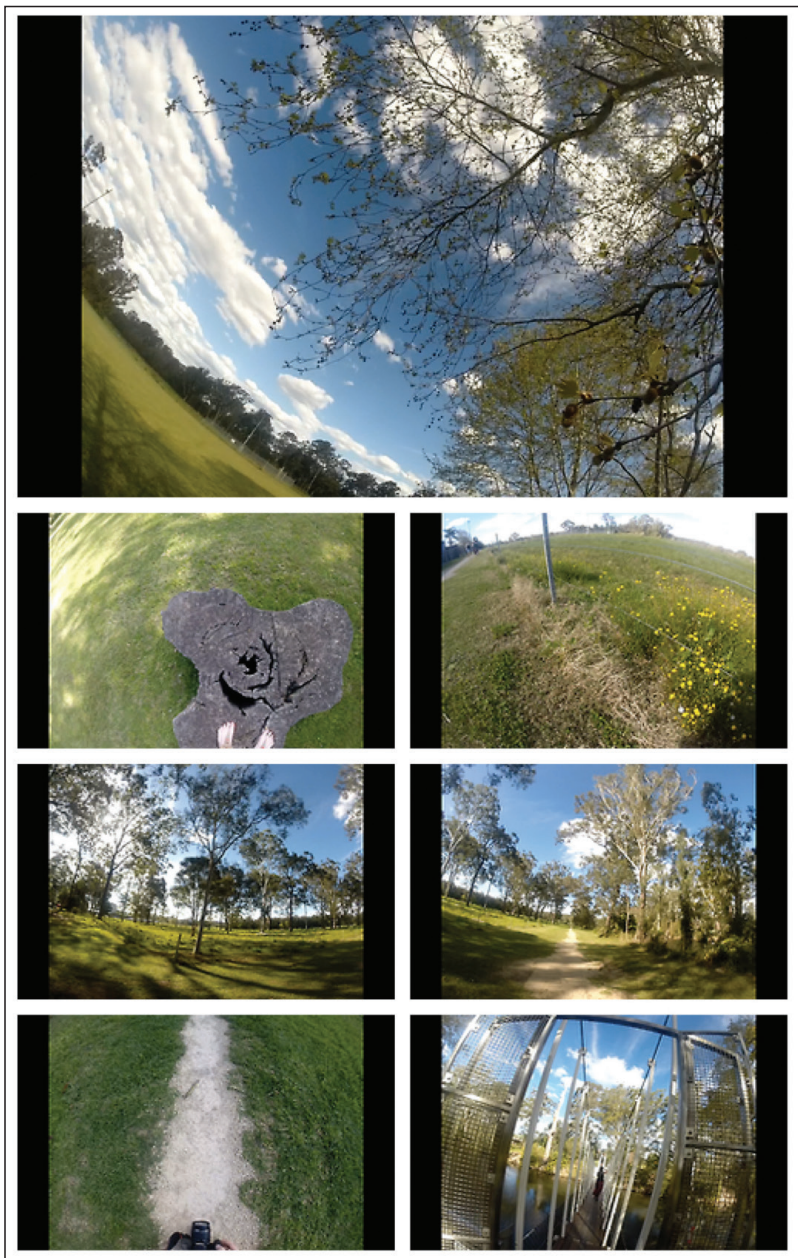

Fig. 1: Felicity Cassie-PPI project gopro screen-capture shots: Shots of eye-level point of view as shooting project

Figure 1 illustrates a visual analysis and curatorial arrangement of her pre-visualization stage images as she evaluated the areas that could be improved upon if re-shooting the project. Felicity ${ }^{1}$ shared the following in her e-learning journal:

I learned a lot by watching myself back. I don't stop and look enough. I find something, take the photo, and leave. I don't spend enough time making sure I got the best photo I could. If I just stopped and took it in, I'm sure I could take not only better photos but more of them. I will defiantly make sure to slow down and take in the big picture in my future projects. 
Felicity was also very aware that she should pay more attention to the technical settings of the camera, such as the ISO (sensor sensitivity to low light) and the aperture, and that more time should be spent reviewing the photos. Felicity stated, "I have an expectation sometimes that the photos I take will be the same as how they look to me through my naked eye. The more I learn, the more I understand that it isn't as simple as that."

In Felicity's post-visualization e-learning blog, she discussed and evaluated her editing techniques and the image selection processes, looking for ways to improve her editing. Time to reflect and view again emerged as more critical when considering the images' message to the intended audience.

I just tend to make it look nice and move on, not looking at the bigger picture. Not thinking about who will be viewing it and how to grab their attention. I will make every effort to change this bad habit in the future.

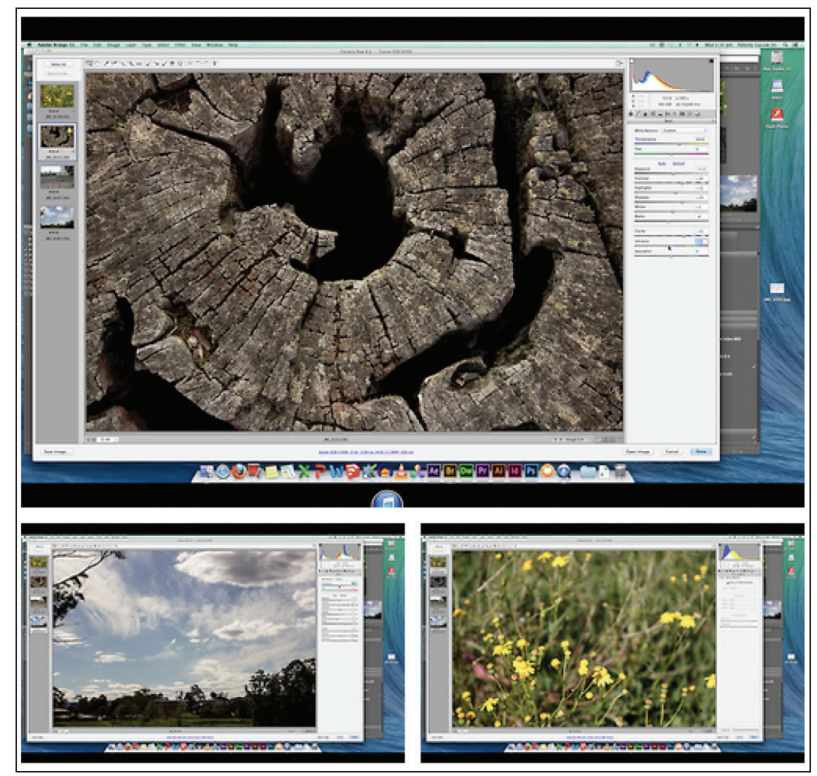

Fig. 2: Felicity Cassie-Project screen shots of editing process

The second participant, Kate Langbein, focused more on visually describing the different editing processes and ideas she had developed for different imagery. Her blog shows examples of before and after cropping of images with edit variations. In addition, the semi-structured interview revealed how she had also used her 
GoPro footage and screen capture video tools to stop and highlight sections she believed to be important or could be improved on. Figure 3 (below) is a more detailed example of her analysis process in editing and selecting ideas.

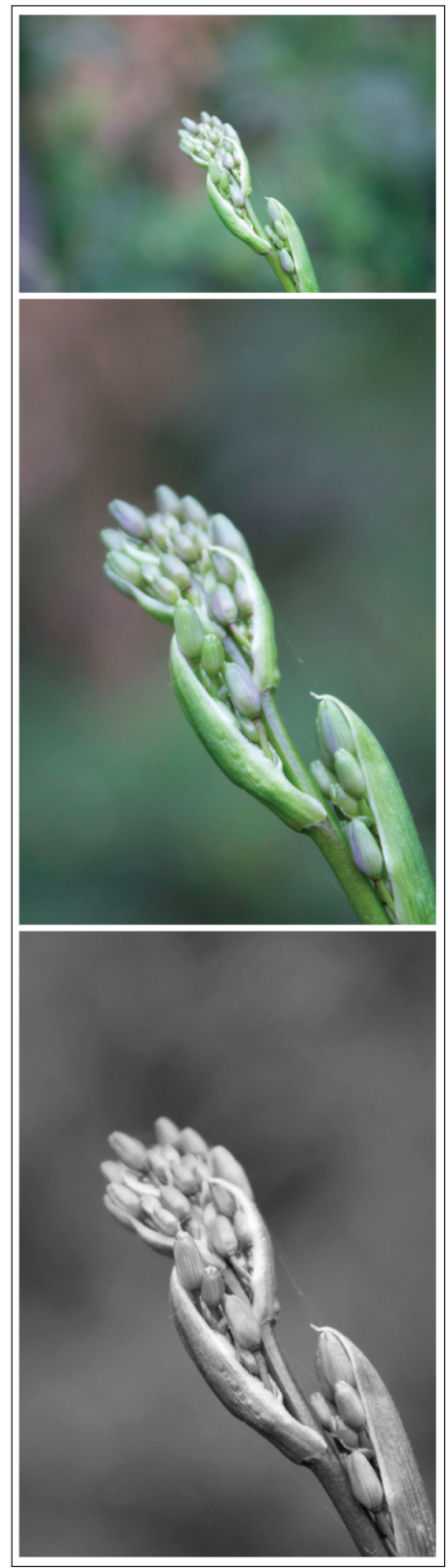

Fig. 3: Kate Langbein-Editing and screen capture 
Student participant Martin Crabtree observed and reflected on the data captured, first showing the angle of view of the shot from the GoPro camera, and then showing the editing process within Adobe Camera Raw. The final image was then shown with a brief statement of the intention behind the photographic image. Martin created a number of these visual observation and analysis entries within his workflow on his e-learning journal. The different images he edited were overlaid within the blog, as well as final posts showing the body of work as a whole.
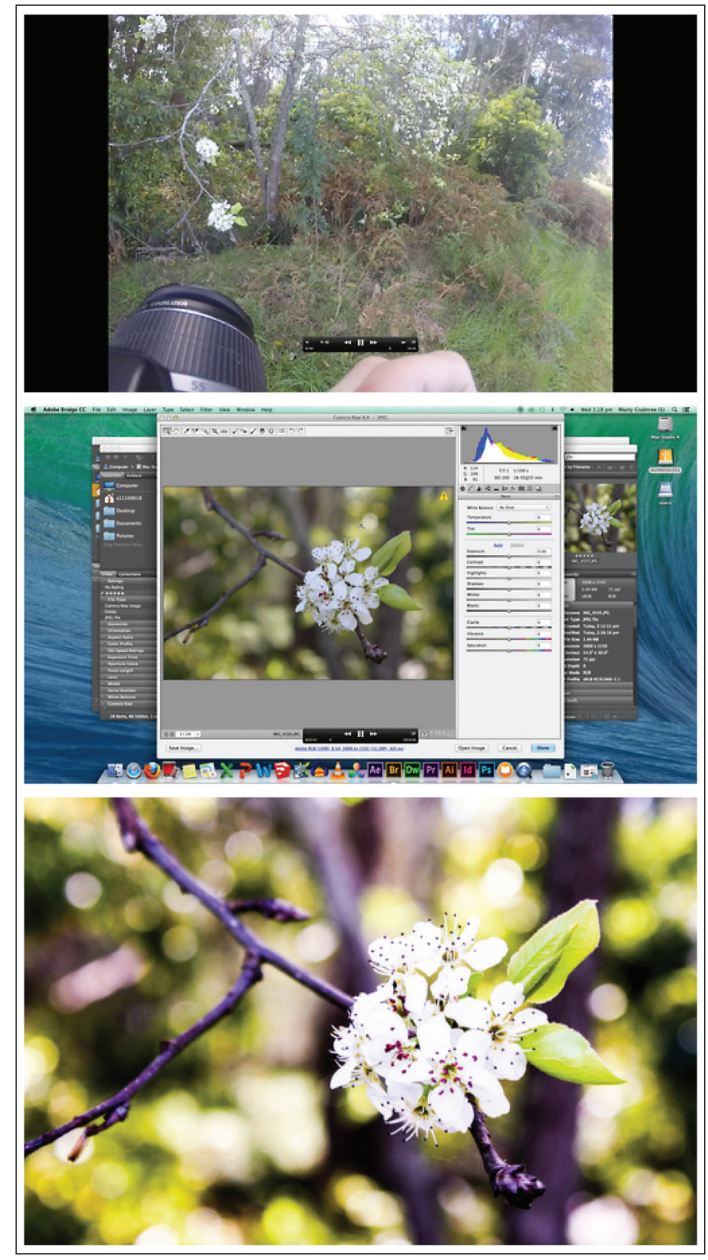

Fig. 4: Martin Crabtree-gopro shot, editing process, final image

I loved the innocence portrayed in this and the white of the flowers really has good character. The angle I went for was to show that the flowers were a part of something much bigger by having the branch go upwards. (Martin Crabtree) 
As illustrated in the examples above, the student participants created diverse methods for analyzing and communicating in their e-journal. While this is only a very small snapshot of the content that each student created on the blog, it provides an insight into the wider class project learning. While students are taught in a lab or studio, they need to learn the skills to interact with the online environment. The e-journal blog is often a new experience, and was conceived to foster more artful aesthetic and reflective practice in the photomedia students. As Lee (2010) describes,

The act of photographing is not merely the act of pressing a button to mechanically fix a part of the world into an image or to reproduce a standardized gaze of photographic conventions. It can also be a practice of being attentive to a series of temporal and spatial moments in the locale and trying to make sense of and interpret a subject. Through the practice of walking around the site, searching for photographable objects, and framing what one wants to capture, one can face the challenge of how to make sense of what one sees. (p. 272)

One of the key benefits of the e-learning journal is that the editing and production dates are embedded so that the information can be tracked in a systematic manner by both the teacher/researcher and the students. The e-journal creates a space and opportunities where the students can view all three phases of the photographs development and it is in the e- journal blog that these iterative and reflective loops can be opened and closed, and revisited endlessly.

\section{Discussion: Artful Inquiry in the E-journal}

For the photomedia teacher, the main function of the e-journal learning space is to help students develop their visual and written reflections about concepts and material practices. It becomes a portal where they work on becoming visually literate through observation, analysis, and reflection, of other photographers' works and their own technical and aesthetic point of views. It is a place to document ideas and processes as well as experiment and reflect on projects. Its importance to educators is that they can have access to the blogs at designated times in order to work collaboratively with students to build aesthetic and critical sensitivities. It also provides them insights into how the co-construction of meaning links to subjectivity and interpretive knowledge and the plasticity of such knowledge, as well as the ability to resist mainstream ideas and build unique aesthetic solutions. 
Interactive reflection and artful inquiry. The personal reflections that follow are those of the artist/researcher/photographer/author. As a teacher-researcher of photography working in an e-learning environment, I have noticed that there are extreme differences across the quality and approaches taken by students when they engage in the analysis of their own imagery to support image production. My observations were reinforced by an external peer reviewer, who also identified that the students were lacking in direction and often reverted to clichéd sentiments such as, "I think this looks beautiful," or "this is great," rather than actually forming an intellectual opinion that takes into account technical and aesthetic knowledge communicated through images or written/spoken texts. To support them in the development of critical language and knowledge, I have encouraged the students to use a guiding framework. This framework builds on photographic theory (Emanuel \& Challons-Lipton, 2013) and includes categories of analysis such as quality and direction of light; composition; depth of field; relations between figure and background; and what is an interpretation of the image.

The inclusion of such a guide and peer discussion within class or through blogging was an important strategy in building more critical, reflective, and creative learning dispositions. Most significantly, the focus on audience as building an "interaction aesthetics" (Xenakis \& Arnellos, 2013) within the design process or the investigation of aesthetic choices was a key pedagogical benefit: "...giving the students the opportunity in class to analyze the same images and then talk about their ideas as a group vastly improved the analysis skills" (author field notes).

The principle behind looking at other photographers and analyzing images is to actually learn techniques, ideas, and approaches to support the construction of a body of work that has relevance to the students' contemporary world.

I have observed for years that students can often have an insulation mentality, and believe that their ideas are original. When I encourage them to research, they suddenly begin to see how many other photographers have explored similar ideas. I experienced this personally as a photography student where I needed to be researching, ideas, techniques of photographers and painters to conceptually and technical improve my artistic practice. (author field notes)

In the e-learning journal I have embedded this thinking, the idea of researching artists within a cyclic phase that can later develop into a professional thinking disposition applied throughout a photographer's career. Not to copy other artists, but to acknowledge the constructed and socially mediated evolution of the 
photographic images and to embed the creation and exploration of ideas as key artistic practices. This in turn ensures that both historical and current industry standards of practice are core learning. The application of this practice has evolved through reflection on my own learning processes and through observing those of my students as they are encouraged to visually explore composition tasks, lighting, and many other techniques documenting this progression in their e-learning journal.

As a photographer, researcher and teacher, I have found in my artistic practice the need to document my process through journals, papers and exegesis on a number of occasions. It has helped me criticize my ideas, informed me and changed my direction on a number of occasions. (author field notes)

What is unique about the digital e-learning journal is that it allows for multiple and iterative learning encounters that are different than the traditional artist journal, seen or read as a more or less linear reflective process, frozen to the page through writing, drawing, and imaged ideas as past experiences. In contrast, the e-learning journal seems to be about evolving one's experience over time. E-journaling allows the learner to shift the learning artefacts and narratives in iterative and non-linear ways through adjusting one's former observations and reflections (Dijck, n.d.), thereby allowing for the contributions of others through the blog to influence the students' personal pedagogical strategies. The e-learning journal can accommodate more recent theories on learning and memory that present narrative and memory as non-linear (Damasio, 2012), influenced by our affective learning (Immordino-Yang \& Damasio, 2007) and core to building adaptive and creative learning dispositions.

E-learning journal and the co-construction of meaning interpretive and subjectivity insights. The focus on pre- and post-visualization ideas within the participatory pedagogy was to build more complexity in the students' analytical and reflexive skills that would help them better understand the considerable impact of their past learning as subjectivity insights when making aesthetic and technical choices. Go-Pro tools have been significant in building this awareness. Rewinding their Go-Pro footage helps them ask:

- What ideas were in their minds as they were shooting?

- What technical elements were they thinking about and contemplating?

- How will they edit or re-imagine the image when they later manipulate it in the computer using imaging software? 
By having conversations with students about creating an e-learning journal and producing new images, the teacher/researcher is able ask the students to verbally describe their learning processes. In addition, the students can follow each other's progress and share techniques and research ideas. Thus, the e-learning journal becomes a portal where the participants, peers, and teacher/researcher can view and engage in the progress, help shape ideas, and support student projects. The benefits of the e-learning platform is that it can simultaneously capture the images, record the thinking and making processes, as well as identify new learning events as they appear during this image-creation phase. For the student, images can now be viewed, reviewed, and narrated upon when reflecting to improve elements for future projects. In addition, it can provide a place where the documenting of the post-visualization process is able to reveal those "in-between spaces" that may lead to an adaption in their technical or aesthetic considerations or shift their thinking to new conceptual insights. In this space, documenting their process of becoming visual creators and designers helps them become aware of their subjectivity as it influences their decision making and reveals opportunities to reflect and change thinking patterns.

New media and the recursive-learning environment. The e-learning journal as new media communication embeds a recursive relationship among images, student-teacher conversations, and the interactive aesthetic. The processes facilitate the foregrounding of the subjective, experience, personal learning observations, and memory work within the recursive process. It allows for repeatedly applying reflection, imaging, and interpretation strategies to the inquiry or research process. The reflection within the multimedia interface of the e-learning journal allows a bridge between the present and the representational and non-representational past, while capturing emotion, time, and subjectivity experiences (Al-Saji 2004).

Student thinking when reflecting, undoing, and redoing is now a documented multiple imaging process. At any point in the development process, images can be digitally modified, curated, and saved. Students can revisit or return to past questions about the technical and interactional aesthetic of their image as they compare their own images to different photographers in conversation with self and others. Nothing in the process is fixed and everything can be changed digitally. Through this process they form collaborative understandings and generate more considered photographs that target a refining of the intentional communicative act of the photographic image being produced. 


\section{Conclusion}

For the photographic teacher/researcher, the challenge to continually refine their pedagogies is complex and ongoing. The challenge of how to best redress the observed lack of considered intentionality in the photographic students' practice, while remaining respectful of the unique learning of each student, is problematic for photographic educators wishing to develop responsive pedagogies. The question of how to best engage students in a manner that enables them to become reflective practitioners to build both the technical and conceptual elements of the creation of an image to meet professional practice standards is ongoing.

Photographic participatory inquiry as a theorized and practical method of teacher research focuses on developing photomedia pedagogies in a tertiary e-learning environment. Its core tool is the e-learning journal that carries a powerful and legitimate means of capturing student digital learning within a co-constructed knowledge context. The purpose of the e-learning journal is to facilitate a recursive process supported by conversations with the teacher and peers through ongoing observation, analysis, manipulation, and curatorial applications of learning moments. In this space, the digital interface provides a new flexibility for independent learners as they engage with the intellectual, emotional, and social dimensions of their learning processes. The key benefit of the e-learning journal and the associated participatory pedagogies is its potential to open up the reflective learning process to the powerful social media and digital tools now accessible to every student and teacher. The e-learning journal facilitates the reflective work of teacher/researchers as they work towards refining the learning process. E-learning visual participatory methods and the design of the e-learning journal may have a wider value as an inquiry method within visual education or general teacher education as teacher educators shift to e-journaling and students increasingly prefer to document their experiences through new digital imaging techniques. Most significantly, the e-learning journal has the benefit of supporting both student and teacher self-study inquiry in the e-feed learning culture.

\section{Note}

1. The authors would like to thank the time and commitment of the three photography students, Felicity Cassie, Kate Langbein, and Martin Crabtree, who willingly gave up their time and shared their learning so that this study could be carried out. 


\section{References}

Adams, A. (1934a). The new photography. In C. G. Holme (Ed.), Modern photography: The studio annual of camera art 1934-35. London: The Studio.

Adams, A. (1934b). The studio annual of camera Art, April 1934 for modern photography 1934-35. Modern Photography.

Al-Saji, A. (2004). The memory of another past: Bergson, Deleuze and a new theory of time. Continental Philosophy Review, 37, 203-239.

Arnold, M. B. (2013). Memory and the brain [Ebook Library version]. Retrieved from http://www. eblib.com

Bailey, N. M., \& Van Harken, E. (2014). Visual images as tools of teacher inquiry. Journal of Teacher Education, 65(3), 241-260. doi:10.1177/0022487113519130

Blinn, L., \& Harrist, A. (1991). Combining native instant photography and photo-elicitation. Visual Anthropology, 4(2), 175-192. doi:10.10 80/08949468.1991.996655

Butler-Kisber, L., \& Poldma, T. (2010). The power of visual approaches in qualitative inquiry: The use of collage making and concept mapping in experiential research. Journal of Research Practice, 6(2), Article M18.

Cope, B., \& Kalantzis, M. (2009). "Multiliteracies": New literacies, new learning. Pedagogies, 4(3), 164-195. doi:10.1080/15544800903076044

Damasio, A. R. (2006). Remembering when. Scientific American Special Edition, 16(1), 34-41.

Damasio, A. R. (2012). Self comes to mind: Constructing the conscious brain. London: Vintage.

Danesi, M. (2010). The history of philosophy as a semiotic process: A note on John Deely's momumental four ages of understanding. Semiotica, 2010(178), 23-37. doi:10.1515/ semi.2010.003

Deleuze, G. (1990). Negotiations. New York: Columbia University Press.
Deleuze, G. \& Guattari, F. (1987). A thousand plateaus: Capitalism and schizophrenia. London: University of Minnesota Press.

Denzin, N. K., \& Lincoln, Y. S. (Eds.). (2005). The SAGE handbook of qualitative research. Thousand Oaks, CA: Sage.

Dewey, J. (1938/1963). Experience and education. New York: Collier.

Dijck, J. van. (n.d.). Composing the self: Of diaries and lifelogs. Retrieved from http://three. fibreculturejournal.org/fcj-012-composingthe-self-of-diaries-and-lifelogs/

Dissanayake, E. (2008). The arts after Darwin: Does art have an origin and adaptive function? In K. Z. a. W. v. Damme (Ed.), World Art Studies: Exploring Concepts and Approaches (pp. 241-263). Amsterdam: Zaliz.

Drew, V., \& Mackie, L. (2011). Extending the constructs of active learning: Implications for teachers' pedagogy and practice. The Curriculum Journal, 22(4), 451-467. doi:10.1080/09585176.2011.627204

Emanuel, R., \& Challons-Lipton, S. (2013). Visual literacy and the digital native: Another look. Journal of Visual Literacy, 32(1), 7-26.

Eppler, M. (2013). What is an effective knowledge visualisation? Insights from a review of seminal concepts. In E. B. F.T. Marchese (Ed.), Knowledge Visualization Currents (pp. 3-12). London: Springer-Verlag.

Finlay, S. (2008). Arts-based research. In J. G. K. A. L. Cole (Ed.), Handbook of the Arts in Qualitative Research. Los Angeles: Sage

Gallagher, K., \& Kim, I. (2008). Moving towards postcolonial, digital methods in qualitative research. In K. Gallagher (Ed.), The methodological dilemma: Creative, critical and collaborative approaches to qualitative research (pp. 103-120). London: Taylor \& Francis.

Grauer, K., \& Naths, A. (1998). The visual journal in context. CSEA Journal, 29(1), 14-19.

Grushka, K., Bellette, A., \& Holbrook, A. (2014). Researching photographic participatory inquiry in an e-learning environment. McGill Journal of Education, 49(3), 621-640 
Grushka, K., Donnelly, D., \& Clement, N. (2014). Digital culture and neuroscience: A conversation with learning and curriculum. Digital Culture \& Education, 6(4), 358-373. Retrieved from http://www.digitalculture andeducation.com/cms/wp-content/up loads/2014/12/grushka.pdf

Grushka, K., McLeod, J. H., \& Reynolds, R. (2005). Reflecting upon reflection: Theory and practice in one Australian University teacher education program. Reflective Practice, 6(2), 239-246. http://doi. org/10.1080/14623940500106187

Guattari, F. (1995). Chaosmosis: an ethicoaesthetic paradigm. Bloomington: Indiana University Press.

Gubrium, A., \& Harper, K. (2009). Visualizing change: Participatory digital technologies in research and action. Practicing Anthropology, 31(4), 2-4.

Harper, D. (2002). Taking about pictures. A case for photo elicitation. Visual Studies, 17(1), 13-26. doi:10.1080/14725860220137345

Hetland, L., Winner. E., Veenema, S., \& Sheridan, K. M. (2007). Studio thinking: The real benefits of visual arts education. New York: Teachers College Press.

Hostetler, K., Macintyre Latta, M \& Sarroub, L. (2007). Retrieving meaning in teacher education: The Question of Being. Journal of Teacher Education, 58(3), 231-244. doi:10.1177/0022487107299977

Immordino-Yang, M. H., \& Damasio, A. R. (2007). We feel, therefore we learn: The relevance of affect and social neuroscience to education. Mind, Brain, and Education, 1(1), 3-10. doi:10.1111/j.1751-228X.2007.00004.x

Irwin, R., \& de Cosson, A. (2004). A/r/tography: Rendering self through arts-based living inquiry. Vancouver, BC: Pacific Educational Press.

Irwin, R. L., \& Springgay, S. (2008). A/r/tography as practice-based research. Arts-Based Research in Education: Foundations for Practice, 103-124.

Jevic, L. L., \& Springgay, S. (2008). A/r/tography as an ethics of embodiment: Visual journals in preservice education. Qualitative Inquiry, 14(1), 67-89. doi:10.1177/1077800407304509
Jones, S. (2010). Common sense assumptions about intentional representation in student artmaking and exhibition in the arts: Initial advice paper. Paddington, AU: Australian Institute of Art Education.

Kemmis, S. (2011). What is professional practice? Recognising and respecting diversity in understandings of practice. Springer. Retrieved from http://link.springer.com/ chapter/10.1007/978-90-481-2605-7_8

Lankshear, C., \& Knobel, M. (2004, December). "New" literacies: Research and social practice. Plenery address. Paper presented at the Annual Meeting of the National Reading Conference, San Antonio, TX.

Lee, D.-H. (2010). Digital cameras, personal photography and the reconfiguration of spatial experiences. The Information Society, 26(4), 266-275. http://doi.org/10.1080/01972 243.2010.489854

Lloyd, M. (2013). Something's coming, something good: Identifying TPACK competence in pre-service teachers' analyses of learning objects. Australian Educational Computing, 28(1). Retrieved from http://journal.acce. edu.au/index.php/AEC/article/view/12

McLoughlin, C., \& Lee, M. J. (2008). The three p's of pedagogy for the networked society: Personalization, participation, and productivity. International Journal of Teaching and Learning in Higher Education, 20(1), 10-27.

Mishra, P., \& Yadav, A. (2013). Rethinking technology \& creativity in the 21 st century. TechTrends, 57(3), 11.

Mockler, N., \& Sachs, J. (Eds.). (2011). Rethinking educational practice through reflexive inquiry: Essays in honour of Susan Groundwater-Smith. New York: Springer.

Pink, S. (2007). Doing visual ethnography. London: Sage.

Pithouse, K., Mitchell, C., \& Weber, S. (2009). Self-study in teaching and teacher development: A call to action. Educational Action Research, 17(1), 43-62. http://doi. org/10.1080/09650790802667444

Samaras, A., \& Roberts, L. (2011). Flying solo. Journal of Staff Development, 32, 42-45. 
Sameshima, P., \& Irwin, R. (2008). Rendering dimensions of a liminal currere. Transnational Curriculum Inquiry, 5(2), 1-15. Retrieved from http://nitinat.library.ubc.ca/pjs/index.php/ yci

Silvia, P. J., Nusbaum, E. C., Berg, C., Martin, C., \& O'Connor, A. (2009). Openness to experience, plasticity, and creativity: Exploring lower-order, high-order, and interactive effects. Journal of Research in Personality, 43(6), 1087-1090.

Springgay, S. (2011). The ethico-aesthetics of affect and a sensational pedagogy. Journal of the Canadian Association for Curriculum Studies, 9(1), 66-82.

Springgay, S. I., R. \& Kind, S. (2005). A/r/tography as living inquiry through arts and text. A Qualitative Inquiry, 11(6), 897-912.

Stafford, B. M. (2007). Echo objects: The cognitive work of images. Chicago: University of Chicago Press.
Uelsmann, J. (2001 to 2002). Maker of photographs: Jerry Uelsmann [Emails, letters and photographs]. Retrieved from http://www. photovisionmagazine.com/articles/uels mann.html

Valdivia, A. N. (2002). bell hooks: Ethics from the margins. Qualitative Inquiry, 8(4), 429-447. doi:10.1177/10778004008004003

Vince, R., \& Warren, S. (2012). Participatory visual methods. In C. C. G. Symon (Ed.), Qualitative organizational research: Core methods and current challenges (pp. 275-295). London: Sage.

Xenakis, I., \& Arnellos, A. (2013). The relation between interaction aesthetics and affordances. Design Studies, 34(1), 57-73. doi:10.1016/j.destud.2012.05.004 


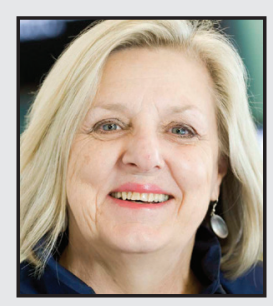

Kathryn Grushka is a Senior Lecturer at the University of Newcastle's School of Education, Visual Arts and Design. Kathryn is known especially for her research work in curriculum, the performative role of artmaking, imaginative becoming, reflective practice, art/science knowing, adaptive knowledge, and transformative learning. Kathryn draws significantly on research methods evolving from arts-based inquiry, visual methods, and narrative methodologies. Kathryn currently sits on international and national editorial teams for art and teacher education journals. She has been the recipient of numerous awards, including the NSW Institute for Educational research, Doctoral Award. In 2005, she received awards for Teaching Quality and Student Learning at both the university and state level.

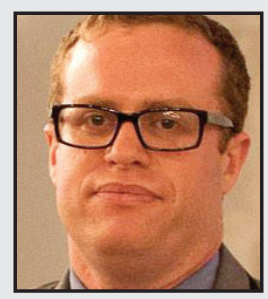

Aaron Bellette is a PhD Research Student at University of Newcastle. He is studying tertiary education focusing on photomedia and how to effectively use e-learning to educate tertiary photography students; how students engage in the process of creating imagery; the expectations of students for using imagery in their work and personal life; and the impact of reflexivity in their work. Aaron is a fine artist, with a focus on photomedia and a higher education lecturer. He has exhibited nationally and internationally for over eight years. 